\title{
Development and Implementation of a Chief Resident for Research Role in a Psychiatry Residency Training Program
}

\author{
Alison R Hwong (D) \\ Stefana Morgan' \\ Chelsea Anne Young ${ }^{2}$ \\ Aaron D Besterman (D) ${ }^{3}$ \\ Michael Jacob' \\ Jody Williams' \\ Victor I Reus' \\ Carol A Mathews ${ }^{4}$ \\ Erick Hung' \\ Susan VogImaier' \\ 'Department of Psychiatry and \\ Behavioral Sciences, Weill Institute for \\ Neurosciences, University of California, \\ San Francisco, CA, USA; ${ }^{2}$ Department of \\ Psychiatry, Stanford University, Palo Alto, \\ CA, USA; ${ }^{3}$ Department of Psychiatry, \\ University of California, San Diego, CA, \\ USA; ${ }^{4}$ Department of Psychiatry, College \\ of Medicine at the University of Florida, \\ Gainesville, FL, USA
}

\begin{abstract}
Psychiatry residency programs with robust research training can prepare physician-scientists to make contributions that advance the mental health field. Our psychiatry residency developed a chief resident for research position to help provide mentorship, community building, and advising around scholarly activities for residents. We present the process of implementing this new position in our residency to offer a model for engaging psychiatry residents in research.
\end{abstract}

Keywords: academic psychiatry, residency training, research career

\section{Introduction}

There is a critical need for more physician-scientists trained in basic, clinical, and public health research in mental health. ${ }^{1,2}$ Psychiatrists, in particular, can play a key role in carrying out translational work that bridges the gap between the rapidly expanding field of neurobehavioral sciences and patient care. ${ }^{3}$ Recently, psychiatry residencies have been gaining popularity among physician-scientist trainees. Encouraging clinician scientists to maintain research momentum throughout psychiatry residency and guiding qualified researchers into the field calls for a robust research program with mentorship spanning the residency training experience. ${ }^{4}$

The Chief Resident for Research (CRR) role was developed to respond to the increasing size of the research track in a large academic psychiatry residency training program and provide near-peer mentorship, support, and leadership. In addition, residents in chief roles have substantial opportunities to develop their own leadership, teaching, and mentorship skills. ${ }^{5}$ Expanding the chief resident model beyond the traditional clinical chief roles increases leadership opportunities, allows for specialization, provides tailored support to residents with diverse career interests, and balances duties among chiefs. Non-psychiatry residencies have introduced novel chief roles, such as the Chief Resident for Research, but few psychiatry programs have followed suit. ${ }^{6}$

This report describes the development and implementation of the CRR role within an adult psychiatry residency training program based at a large academic institution in the United States. Since 2015, the residency program has appointed one CRR each year. This psychiatry residency training program has a research track that aims to expand the pipeline of psychiatrist researchers. Time dedicated to research increases throughout residency, from 5\% during intern year to $>75 \%$
Correspondence: Alison R Hwong University of California, San Francisco, Department of Psychiatry and Behavioral Sciences, Weill Institute for

Neurosciences, 40I Parnassus Avenue, Box 0984, San Francisco, CA, 94I430983, USA

Tel + I 4064147185

Email alison.hwong@ucsf.edu 
time during the postgraduate year 4 (PGY-4). The goal of the program is to provide protected time, mentorship, and funding for research during residency, resulting in graduating residents who can successfully obtain postdoctoral or faculty research positions that will launch a career in psychiatric research. $^{7}$

Though the majority of psychiatry residency training programs do not have grant-funded research tracks, there is a need for additional opportunities for robust leadership training for physician-scientists. ${ }^{8}$ The goal of this report is to illustrate how our experience can serve as one model for other training programs interested in appointing a CRR to support residents interested in research in their institutions.

\section{Development and Description of the Chief Resident for Research Role}

The role for a CRR in our residency training program was proposed by research residents in 2014, spurred by the creation of a Chief Resident for Education position during an overhaul of the didactic curriculum. Residents recognized that a CRR could play a unique role in optimizing the integration of the research track within the new curriculum. In addition, the number of residents applying into the research track or conducting scholarly activities was increasing, highlighting the need to foster a sense of community among research residents and faculty.

The residency program director, the faculty director of the research track, and research track residents conducted a needs assessment for the CRR proposal. The needs assessment identified expected benefits as well as potential concerns around the new chief role. Expected benefits of a CRR role included a research-oriented voice in didactic planning, mentoring, increased scholarly output, and leadership at research-related events. Concerns for creating a CRR role included the difficulties that might arise in balancing chief responsibilities with the resident's own scholarly activities.

A literature search identified examples of CRRs from other specialties. $^{9-11}$ At the time, only one other CRR in a US psychiatry residency training program existed, and discussion with the chief in this program provided insight into potential roles and responsibilities. The working group held informal focus groups with research and nonresearch track residents, other chief residents, and program staff to conceptualize and gauge support for a CRR role.

Needs identified by the brainstorming process included: 1) assisting trainees in navigating the research track, 2) improving participation in journal clubs and seminars, and 3) helping to develop a neuroscience curriculum for all residents. Benefits for the resident serving as CRR included training in leadership in science to become a more effective research mentor and manager. In addition, the CRR would have regular meetings with senior departmental leadership, acting as a liaison between research residents and the Vice Chair for Research, as well as the research track and residency training directors.

Based on evidence of the benefits of near-peer mentorship and peer-assisted learning in other programs, ${ }^{12,13}$ a consensus was reached that a PGY-4 research track resident would be most attuned to provide mentorship to research track peers with specialized knowledge related to research and scholarship methodology. Senior residents can serve as effective educators and mentors to junior residents due to the proximity in career stage, which allows for both social and cognitive congruence between near-peers. ${ }^{12,13}$ A PGY-4 CRR could also translate their near-peer understanding of current research residents' needs to the clinical and education chiefs and residency training program leadership.

The potential duties of the CRR were then presented to a formal working group composed of faculty, residency training program leadership, and residents, who further helped to refine the list of duties through a consensusbuilding process. The working group articulated these major aims of the CRR role and duties:

1. To foster community and belonging amongst research residents.

2. To improve research opportunities, visibility, and outcomes for residents engaged in scholarly activities.

3. To serve as a liaison between research residents and residency leadership, and help connect residents to research opportunities at our institution and nationally.

4. To help recruit new residents interested in pursuing research during residency.

5. To assist with planning and implementation of basic neuroscience and evidence-based psychiatry education through didactic planning, journal clubs, research resident retreat, and works-in-progress sessions.

6. To develop a legacy project that leaves lasting infrastructure in the residency training program to support scholarly activity.

Importantly, the CRR also provides mentorship around the hidden curriculum of academic research - helping 
residents decide whether or not to pursue research careers, advocating for balance between research and clinical obligations, promoting awareness of gender and racial bias in academia, and navigating relationships with mentors, peers, and the department. ${ }^{14,15}$

Working group members emphasized the need to align the CRR role with the larger mission of all chief resident positions to further the goals of the residency training program. Chiefs work collaboratively with residents, residency training program leadership, and site- or servicespecific leadership to optimize the quality of training, including residents' well-being. Furthermore, the research track operation would not be chief-dependent; that is, the program would remain fully functional without the chief. This would protect the primary focus of the resident who would take on the CRR role and also have an ongoing research project outside of CRR duties. To maintain protected research time, the CRR role requires half the amount of time as the traditional chief roles (only 10\% instead of $20 \%$ of full-time equivalent [FTE]).

\section{From Concept to Implementation}

Funding for the proportion of time allocated to the CRR position (eg, 10\% FTE) was supported by the department. The authors recognize that funding for non-clinical time can be challenging for residency training programs and is highly variable across institutions. Some institutions rely on professional fees from faculty practices, clinical revenue generated by departments, donor funding, or more flexible funding sources, such as through local health systems. For programs unable to fund time for a chief position, residencies can provide alternative incentives such as call assignment reductions.

A description of the CRR role, including learning objectives and responsibilities (Box 1) was approved by residency training program leadership and the new position was announced to the resident body. Applications for all chief positions, including the CRR, were first solicited for the 2015-2016 academic year.

As with all chief resident positions, the CRR position benefits from weekly mentorship and professional development from the residency training program director. Professional development goals include discussing models of system improvement, discussing change management models, reflecting on leadership styles and leadership models, negotiating conflict, and practicing effective teaching and mentorship strategies.

\section{Lessons Learned}

As the role was being developed, the team recognized the need for clearly structured guidelines describing the role. However, in addition to clarity around the roles and

Box I Learning Objectives and Responsibilities of Chief Resident for Research

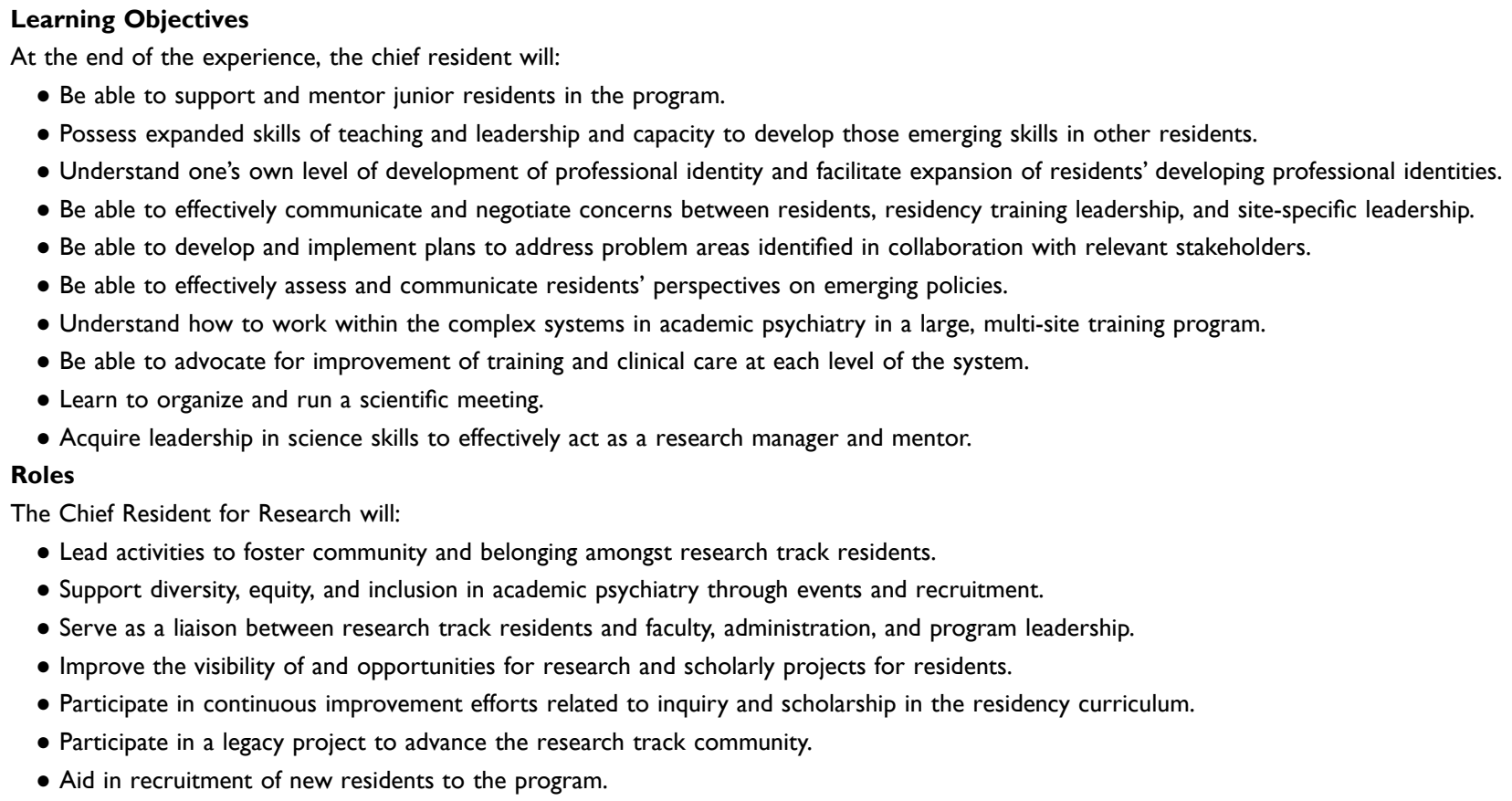


responsibilities of the CRR, the need for flexibility within the role emerged as an important principle. Flexibility within the CRR role not only aligns with the changing nature of the needs of the residents and program, but also accommodates the diverse interests and skills that each chief brings to the position. Finally, the need for time management and prioritization of learning and primary research career development for the CRR became apparent as excessive involvement in research chief-related activities can leave inadequate time for primary research projects.

In evaluating the CRR role since its inception six years ago, former CRRs identified the importance of the CRR in guiding and mentoring other residents, in collaborating with the research track director, and in building a research community. While the formal CRR responsibilities largely address curriculum planning and communicating with residency leadership, the CRR's most significant role may be in helping research residents navigate the developmental milestones of a clinician-scientist. Former CRRs noted that, in some cases, the CRR helps residents decide whether or not they should participate in the research track, which potentially has tremendous influence on their career trajectory. The CRR also guides some research track residents in selecting a mentor, which has bearing on their project success. CRRs also advised residents around learning to balance research and clinical duties, integrating research and clinical expertise to maximize productivity, and planning for next stages after residency (eg, academic and industry positions).

Comparison of a resident cohort from a five-year period prior to implementation of the CRR role (2010-2015) with a cohort with a CRR (2015-2020) reveals some differences. The number of participating residents increased from 20 to 24 , while attrition decreased from $3(15 \%)$ to $2(8.3 \%)$. Of those who completed the program, 11/17 (64.5\%) residents from the earlier cohort went on to research fellowships or positions, while 18/24 (75\%) from the later cohort did. The number of residents who secured research faculty or staff positions directly out of residency increased from $1 / 17$ (5.9\%) to $3 / 22(13.6 \%)$. While the CRR may not be the only factor in increasing research career interest among residents, the role established the value of research in our residency program and provided additional mentorship to residents to balance clinical and research responsibilities.

Each resident used the legacy project component of the role to customize the position to fit their interests while responding to program needs. Legacy projects of the CRRs included the following:
- Near-Peer Mentorship: Development of interest groups based on research area (basic science, clinical/translational, and health services/public health). These small groups include residents across all years, providing vertical peer mentorship.

- Diversity, Equity, and Inclusion Capacity Building: Creation of a group for women in the research track to address issues of gender equity in academic psychiatry. The group offers talks on salary negotiation, leadership, and public speaking, along with facultyresident gatherings.

- Statewide Research Resident Retreat: Planning and running an annual retreat for research residents in psychiatry around the state. This event is coordinated with other research track programs and involves scholarly talks and career development activities. ${ }^{16}$

- Learning Plans: Updates to the annual Individual Learning and Development Plans with timelines and goals specifically relevant to research career development.

- Curriculum Planning: Revisions to the resident neuroscience course using principles based on the National Neuroscience Curriculum Initiative. This update also led to the resident curriculum incorporating teaching on statistical methods for reading and interpreting journal articles.

- Research Ethics Training: Development of an innovative research ethics game for the statewide research resident retreat, an activity that is now used annually.

In terms of generalizability, the CRR role provides research track residents with opportunities for leadership training as physician-scientists to improve the educational experience for all residents. Importantly, aspects of this model can also be implemented in psychiatry training programs that do not have a defined research track. In these environments, the CRR could be responsible for helping interested residents identify scholarly projects and potential mentors, creating near-peer groups to assist with the practical aspects of conducting such a project, and helping residents to prepare for publication or conference presentations. The CRR can assist with recruiting research-oriented residents and also support residents without prior research experience to develop necessary skills. The benefits of such a position to the department may include an increase in scholarly activity (and output) among residents, and possibly also among faculty, as well as providing an avenue for input into the educational curriculum, as was the case in our 
institution. If specific funding sources are not available for the creation of a CRR, as discussed earlier, alternative incentives, such as reduced call, could be considered.

Future directions for our residency training program's research track and CRR role include ways to support scholarly activity amongst residents who do not intend to pursue a research career but may be interested in study collaborations or quality improvement projects. In a 2020 survey, the psychiatry training program's research residents also identified the need to build a more cohesive community for research residents as a priority for the CRR. The survey responses made clear that given the challenges of balancing research and clinical work, research residents sought out likeminded peers and mentors to bolster their commitment to research careers. The CRR could partner with chief residents in neurology and similar fields to develop a broader research community in the neurosciences. Connecting to other residency program research residents across institutions may foster this type of support as well. Finally, the CRR could help with efforts towards recruitment and retention of trainees from historically underrepresented groups in psychiatric research, an important goal for our institution and field.

With the growing need for skilled physician-scientists in psychiatry, residency programs will need to make developing research capacity a key training goal. Our program's CRR model offers a novel approach for establishing the importance of developing research leadership skills during psychiatry training and preparing research track residents for careers in academic medicine.

Ethical Review: University of California, San Francisco Institutional Review Board approval was not required for this research as this was considered a nonclinical quality improvement activity with the limited intent of evaluation and improving existing services and programs or for developing new services or programs.

\section{Funding}

This work was supported, in part, by a grant from the National Institute of Mental Health to Drs. Voglmaier and Reus (R25 MH060482).

\section{Disclosure}

Dr Carol A Mathews reports grants from NIH, during the conduct of the study; book royalties from WW
Norton \& Co, grants from NIH and IOCDF, outside the submitted work. The authors report no other conflicts of interest, including financial or personal relationships with individuals or entities that may have influenced this work.

\section{References}

1. McLellan F. Research by US psychiatrists in danger of extinction. Expert committee recommends steps to strengthen research training in psychiatry residency. Lancet. 2003;362(9397):1732. doi:10.1016/ S0140-6736(03)14893-3

2. Chung JY, Insel TR. Mind the gap: neuroscience literacy and the next generation of psychiatrists. Acad Psychiatry. 2014;38(2):121-123. doi:10.1007/s40596-014-0054-6

3. Fenton W, James R, Insel T. Psychiatry residency training, the physician-scientist, and the future of psychiatry. Acad Psychiatry. 2004;28(4):263-266. doi:10.1176/appi.ap.28.4.263

4. Blacker CJ, Morgan RJ. Research tracks during psychiatry residency training. Acad Psychiatry. 2018;42(5):698-704. doi:10.1007/s40596018-0897-3

5. Warner CH, Rachal J, Breitbach J, et al. Current perspectives on chief residents in psychiatry. Acad Psychiatry. 2007;31(4):270-276. doi:10.1176/appi.ap.31.4.270

6. Ruiz J, Wallace EL, Miller DP, et al. A comprehensive 3-year internal medicine residency research curriculum. Am J Med. 2011;124 (5):469-473. doi:10.1016/j.amjmed.2011.01.006

7. Tsai AC, Ordóñez AE, Reus VI, et al. Eleven-year outcomes from an integrated residency program to train research psychiatrists. Acad Med. 2013;88(7):983-988. doi:10.1097/ACM.0b013e318294f95d

8. Meador CB, Parang B, Musser MA, et al. A workshop on leadership for senior MD-PhD students. Med Educ Online. 2016;21(1):31534. doi: $10.3402 /$ meo.v21.31534

9. Strohbehn GW, Tapper EB, Del Valle J. Transforming chief residents into chief scholars. Med Sci Educ. 2019;29(4):1135-1139. doi:10.1007/s40670-019-00777-3

10. Catanzariti AR, Mendicino RW, Practical A. Approach to research during residency training. Clin Podiatr Med Surg. 2007;24 (1):95-101. doi:10.1016/j.cpm.2006.08.004

11. Biese K, Leacock BW, Osmond CR, et al. Engaging senior residents as leaders: a novel structure for multiple chief roles. J Grad Med Educ. 2011;3(2):236-238. doi:10.4300/JGME-D-10-00045.1

12. Lockspeiser TM, O'Sullivan P, Teherani A, et al. Understanding the experience of being taught by peers: the value of social and cognitive congruence. Adv Health Sci Educ Theory Pract. 2008;13(3):361-372. doi:10.1007/s10459-006-9049-8

13. Ten Cate O, Durning S. Dimensions and psychology of peer teaching in medical education. Med Teach. 2007;29(6):546-552. doi:10.1080/ 01421590701583816

14. Hafferty FW. Beyond curriculum reform: confronting medicine's hidden curriculum. Acad Med. 1998;73(4):403-407. doi:10.1097/ 00001888-199804000-00013

15. Torralba KD, Jose D, Byrne J. Psychological safety, the hidden curriculum, and ambiguity in medicine. Clin Rheumatol. 2020;39 (3):667-671. doi:10.1007/s10067-019-04889-4

16. Besterman A, Williams JK, Reus VI, et al. The Role of Regional Conferences in Research Resident Career Development: the California Psychiatry Research Resident Retreat. Acad Psychiatry. 2017;41(2):272-277. doi:10.1007/s40596-016-0562-7 


\section{Publish your work in this journal}

Advances in Medical Education and Practice is an international, peerreviewed, open access journal that aims to present and publish research on Medical Education covering medical, dental, nursing and allied health care professional education. The journal covers undergraduate education, postgraduate training and continuing medical education including emerging trends and innovative models linking education, research, and health care services. The manuscript management system is completely online and includes a very quick and fair peer-review system. Visit http://www.dovepress.com/testimonials.php to read real quotes from published authors.

Submit your manuscript here: http://www.dovepress.com/advances-in-medical-education-and-practice-journal 